\title{
Reported prevalence of suicidal ideation and suicide attempts among men who have sex with men in China: A systematic review and meta- analysis
}

Hanlin Fu

Shenzhen center for disease control and prevention

Tubao Yang

Central South University Xiangya School of Public Health

Xiaobing Wu

Shenzhen Center for Chronic Disease Control

Yumao Cai

Shenzhen Center for Chronic Disease Control

tiejian feng ( $\square$ fengtiej@126.com)

Shenzhen Center for Disease Control and Prevention

\section{Research article}

Keywords: MSM, suicidal ideation, suicide attempts, meta-analysis

Posted Date: December 4th, 2019

DOI: https://doi.org/10.21203/rs.2.18100/v1

License: (9) This work is licensed under a Creative Commons Attribution 4.0 International License. Read Full License 


\section{Abstract}

Background: Men who have sex with men(MSM) in China are at high risk for suicidality but often overlooked. Several studies have reported the prevalence of suicidal ideation and suicide attempts. However, the estimates varies substantially between studies. This systematic review aimed to establish pooled prevalence of suicidal ideation and suicide attempts among MSM in China, in order to arouse the attention of the public.

Methods: The relevant studies up to April 2019 were systematically searched via several electronic databases. Studies were screened according to inclusion and exclusion criterion and the random-effects meta-analyses were adopted to calculate the pooled prevalence estimates of suicidal ideation and suicide attempts. Heterogeneity between studies and publication bias was also assessed.

Results: A total of 23 articles were eligible for the meta-analysis. The pooled prevalence estimate of suicidal ideation and suicide attempts was $20.1 \%$ (95\% Cl: $16.7 \%-23.7 \%)$ and 6.8\%(95\% Cl: 5.0\%-8.9\%), respectively. Significant heterogeneity was found for both combined effects. Heterogeneity in the estimates could be partially explained by survey points, HIV infection and average age.

Conclusions: The prevalence of suicidal ideation and suicide attempts among MSM in China was moderate high, suggesting that more attention should be paid to the subgroup and effective psychological interventions need to be established and implemented to reduce the suicide-related problems among Chinese MSM.

\section{Strengths And Limitations Of This Study}

- This is the first systematic review and meta-analysis to provide a comprehensive estimate of the prevalence of suicidality among MSM in China.

- The study highlighted that suicidality among MSM is a pressing issue and a great public health challenge for China.

- The findings suggested that more attention and effective psychological interventions was urgently provided to prevent and reduce the suicide-related problems among Chinese MSM, especially for HIV-positive MSM.

- The substantial heterogeneity across individual studies remained unexplained by the variables examined.

- The non-probability sampling methods used in all included studies will lead to a bias of the pooled prevalence.

\section{Background}

Empirical studies have documented that men who have sex with men (MSM) are vulnerable to mental disorders, including depression, anxiety, and even suicide ${ }^{1-5}$. According to one of the prevailing explanatory framework termed minority stress theory, MSM often experience strong social discriminations, prejudice, internalized stigma and self-unacceptance due to their sexual identity and behaviors, which in turn contribute to poorer mental health outcomes ${ }^{6}$. As a major public health issue, suicide among MSM has been focused on recent years.

Suicide can be recognized as a sequence of complex psychological process starting with suicidal ideation and ending in one's own death ${ }^{7}$.Suicidal ideation and suicide attempts are two important precursors of suicide completion. It has been well established that MSM are more likely to report suicidal ideation and suicide attempts compared with general male population ${ }^{4} 5$ - 11 . One meta-analysis conducted by King and his colleagues showed that the risk for lifetime suicidal ideation was nearly two times higher in gay and bisexual men than their heterosexual counterparts, for lifetime suicide attempts nearly four times higher ${ }^{5}$. Another meta-analysis involving 19 literatures indicated that the prevalence of lifetime suicidal ideation among MSM was 34.97\%, far higher than that among general population ${ }^{12}$. Therefore, more care and effective psychological interventions were urgently in need for MSM.

In China, there are an estimated 21.0 million MSM aged 15 to 64 years ${ }^{13}$. With the openness of attitudes toward sexuality and removal of homosexuality from the list of mental disorders in the third version of the Chinese Classification of Mental Disorders(CCMD-3) ${ }^{14}$, societal perception of homosexuality has gradually been improved. Nevertheless, the tolerance and acceptance to homosexual behavior in general Chinese people is still not high within the context of traditional culture ${ }^{15} 16$.In addition, influenced by the epidemic of HIV, MSM in China are even highly stigmatized, leading to an elevated prevalence of suicidal behaviors. In the past two decades, several studies have reported the prevalence of suicidal ideation and suicide attempts among Chinese $\mathrm{MSM}^{10}$. However, the estimates ranged greatly across studies, from $10.2 \%$ to $48.0 \% 41718$ and $2.7 \%-17.7 \% 41819$, respectively. Knowledge gaps still exist in our better understanding of the precise epidemiologic burden of suicide among MSM in China. Moreover, in view of the hidden nature of MSM population, it is difficult to reach the members of the MSM for a national epidemiological survey to assess their mental health status. Therefore, we performed the meta-analysis to obtain pooled prevalence estimates of suicidal ideation and suicide attempts among MSM in China, in order to have a knowledge of their suicidality and arouse the attention of the government and society to MSM. 


\section{Methods}

We performed this meta-analysis following the Preferred Reporting Items for Systematic reviews and Meta-Analyses (PRISMA) guidelines ${ }^{20}$.

\section{Literature Search and Selection}

The relevant articles were systematically searched in PubMed, Embase, Wed of Science, Chinese National Knowledge Infrastructure, China Biology Medicinedisc, Chongqing VIP database for Chinese Technical Periodicals, and Wanfang Databases from inception to April 1, 2019. A combination of the following search terms was used: (( ' $m a n$ ' OR 'male' OR 'men') AND (homosexual* OR bisexual* OR androphilia OR 'samesex')) OR 'men who have sex with men' OR 'gay') AND (suicidal OR suicide) AND (Chinese OR China).Additionally, a manual search was performed to screening reference lists of the previous systematic reviews and other relevant articles to find potential relevant studies.

All retrieved literature were imported into Endnote X8.2 software to remove duplicates. Eligible studies were included in the review if they: 1) were conducted among MSM in mainland China; 2) were conducted after 2005; 3)were published either in English or Chinese; 4) provided adequate information on the prevalence estimation of suicidal ideation or suicide attempt. On the contrary, studies that met any of the following criteria were excluded: 1) studies that were systematic reviews or qualitative interview studies; 2) studies that were duplicate publications; 3 ) studies that didn't provide the prevalence estimation or sufficient data for the prevalence calculation; 4)studies that were conducted before 2005 or didn't provide survey dates. Additionally, for multiple studies using the same sample, only studies that presented detailed and comprehensive information were retained.

All the work above was independently completed by two researchers. Any discrepancy was resolved by discussion to reach a consensus.

\section{Data Extraction}

Using a standardized form, two researchers independently extracted the following information from each eligible study: first author, publication year, survey dates, study location (city), sampling method, method of data collection, average age of subjects, sample size, number of events, survey point (i.e. past one month, past six months, past one year or lifetime), characteristic of subjects (i.e. status of HIV infection). Inconsistent data extraction were resolved by discussion or reconciled by the primary author if necessary.

Due to the methodological limitations concerned with the special population, traditional quality assessment tools were not well-suited to appraise individual articles. For example, the representativeness of sample, an important indicator of quality in the assessment tools, was poor as a result of non-probability sampling used in nearly all included studies. Therefore, following the Meta-analysis of Observational Studies inEpidemiologyguidelines ${ }^{21}$, we instead analyzed the effect of risk-of-bias variables (i.e. sampling method and method of date collection) on the pooled prevalence estimates, as did in the previous studies ${ }^{922}$.

\section{Statistical Analysis}

All statistical analyses were performed using the meta package in $R 3.5 .0$ software. In view of the potential between-study heterogeneity, the random-effects meta-analyses were adopted to calculate the pooled prevalence estimates of suicidal ideation and suicide attempts with their corresponding95\% confidence intervals (Cls). Heterogeneity between studies was assessed using Cochran's chi-squared test(Cochran'sQ) and $P^{2}$ values, in the case of which $P<0.1$ or $P^{2} \geq 50 \%$ was considered moderate or high heterogeneity.

Subgroup analyses were conducted to examine whether the pooled prevalence estimates differed by survey dates (2010 before vs 2010 after), study location(northern city vs southern city), sampling method (respondent-driving sampling vs non respondent-driving sampling), method of data collection (face-to-face interview and self-administered), survey point, HIV infection (HIV-positive vs HIV-negative). A random-effects metaregression was performed to identify the impact of covariates (i.e. average age and sample size) on the effect sizes.

Besides, sensitivity analysis was conducted by serially excluding each included study to detect the effects of single studies on the robustness of the combined prevalence. For the assessment of publication bias, a visual inspection of funnel plots along with Egger's tests was used. All tests were two-sided and a $P$-value $<0.05$ was considered statistically significant.

\section{Results}

\section{Study selection and characteristics}


A total of 248 articles were collected during the literature search. Based on the inclusion and exclusion criteria, 23 articles were eligible for the meta-analysis, among which 22 articles reported on the prevalence of suicidal ideation $(n=10664)$ and 15 articles reported on the prevalence of suicide attempt $(n=6412)$ (Fig 1). All the articles were conducted during 2005-2017. The sample size of the individual studies ranged from 62 to 1809. Among them, 17 were conducted in southern China, 4 were conducted in northern China, 1 were conducted across two areas and 1 did not report the survey location. In terms of sampling method, 16studies used respondent-driving sampling and7studies used non-respondentdriving sampling. In regard to assessment methods, 8 studies used self-administered method, 12 studies used face-to-face interview method and 3 studies did not report the information. As to survey point, 12 studies reported the life time prevalence of suicidal ideation, 6 studies reported the prevalence over the past year, 2 studies reported the prevalence over the past six month and 2 studies reported the prevalence of suicidal ideation over the past month. 13 studies reported the life time prevalence of suicide attempts and2 studies reported the prevalence over the past six months. Additionally, 2 studies reported the prevalence of suicidal ideation on HIV-negative MSM and 7 studies reported on HIVpositive MSM. An overview of the characteristics of the included studies was presented in Table 1.

\section{Pooled prevalence}

The prevalence of suicidal ideation and suicide attempts among MSM varied considerably in eligible studies, ranging from7.0\% to $48.0 \%$ and $2.7 \%-17.7 \%$.For suicidal ideation among MSM, the pooled prevalence estimate was $20.1 \%(95 \% \mathrm{Cl}: 16.7 \%-23.7 \%)$,and for suicide attempt, the pooled estimate was $6.8 \%(95 \% \mathrm{Cl}: 5.0 \%-8.9 \%)$.(Fig.2 and Fig.3) Significant heterogeneity was found for both combined effects $(P<0.001, P=$ $94.8 \%$ and $R=88.0 \%)$. More specifically, the estimates for lifetime suicidal ideation was $22.6 \%(95 \% \mathrm{Cl}: 18.2 \%-27.4 \%)$, for past year suicidal ideation was $21.2 \%(95 \% \mathrm{Cl}: 13.8 \%-29.7 \%)$, for past 6 months suicidal ideation was $13.4 \%(5.7 \%-23.5 \%)$, for past month suicidal ideation was 10.3\%(95\% Cl: $8.1 \%-12.8 \%)$, for lifetime suicide attempts was $7.2 \%(95 \% \mathrm{Cl}: 5.2 \%-9.5 \%)$, and for past 6 months suicide attempts was $4.4 \%$ (95\%Cl: $2.5 \%-6.7 \%)$. Notably, there were significant differences in pooled estimates of suicidal ideation and suicide attempts when grouped by survey point $(P<0.05)$

\section{Subgroup analysis and meta-regression}

Subgroup analyses were performed for studies on suicidal ideation and suicide attempts by study or sample characteristics(Table 2 ). When stratified by HIV infection status, the pooled prevalence estimates of suicidal ideation among HIV-positive MSM (27.1\%, $95 \% \mathrm{Cl}$ : $17.6 \%-37.8 \%)$ was far higher than that among HIV-negative MSM (12.4\%, 95\% Cl: 8.2\%-17.3\%). Nevertheless, there were no significant between-group differences in pooled estimates of suicidal ideation or suicide attempts when studies were grouped by survey dates, study location, sampling method and method of data collection. In the meta-regression analyses, the prevalence of suicidal ideation substantially increased with the average age $(=0.016, P=0.017)$, but didn't significantly vary with the sample size $(=-0.005, P=0.351)$. There were no significant associations between average age $(=0.002, P=0.715)$, sample size $(=0.003, P=0.550)$ and the prevalence of suicide attempts.

\section{Sensitivity analysis}

By serially repeating the meta-analysis while omitting each study, both the pooled estimates didn't vary by more than $1 \%$, indicating that the results were relatively stable. (see Supplementary file Fig. S1 and Fig. S2)

\section{Publication bias}

The funnel plots for studies on suicidal ideation and suicide attempts appeared symmetrical by visual inspection, and the Egger's tests suggested there was no publication bias for these two meta-analyses. (Fig. 4)

\section{Discussion}

To our knowledge, this is the first meta-analysis to estimate the pooled prevalence of suicidal ideation and suicide attempts among MSM in China. Totally, 23 articles with 10664 participants were included in the analysis. The results indicated that the prevalence of suicidal ideation and suicide attempts among Chinese MSM were $20.1 \%$ and $6.8 \%$, respectively, implying that nearly one in five MSM thought about suicide and seven in one hundred MSM had attempted suicide. Apparently, these figures are far higher than those reported in the general male population of China, for example, only $2.8 \%$ for lifetime prevalence of suicidal ideation and $0.5 \%$ for lifetime prevalence of suicide attempts ${ }^{42}$. Our findings was also basically consistent with a recent meta-analysis which presented that the lifetime prevalence of suicidal ideation among MSM was $25.8 \%$ in low- and middle- income countries ${ }^{12}$. Overall, the results highlighted that suicidality among MSM is a pressing issue and a great public health challenge for China. 
In recent years, the prevalence of HIV was increasing at an alarming rate among MSM throughout China ${ }^{43}$. Some studies have reported that MSM living with HIV were more likely to develop mental disorders ${ }^{34} 4445$, because they not only faced pressure from homosexuality-related stigma but also HIV-related stigma against them, which were both considered to be potential predictors of suicide 5113446 . In our study, the pooled prevalence estimates of suicidal ideation was 27.1\% among HIV-positive MSM, far higher than that among HIV-negative MSM. The result was in accordance with another previous review ${ }^{12}$, suggesting that HIV-positive MSM should be taken seriously and provided more psychological supports.

As mentioned above, homosexuality has been removed from the CCMD-3 as a mental disorder in China in $2001^{14}$. Changes in the domestic social environment promoted the public's attitude toward MSM to be moderate and tolerant, helping MSM population adapt to their lives. Therefore, we selected studies conducted after 2005 in order to identify if any changes in the prevalence of suicidality exist over time. Indeed, compared to research findings around 2001 which presented the lifetime prevalence of suicidal ideation among MSM was 34.5\%-39.6\% $47-49$, the result of this study is much lower. However, there was no significant difference in combined prevalence estimates between articles studied before and after 2010. Moreover, respondent-driving sampling (RDS), recognized as an approximating random sampling method, has been widely used for recruiting hard-to-reach populations and proved to generate unbiased population estimates ${ }^{50} 51$. However, no significant difference was observed in our study when grouped by sample method, so was the survey method and survey place.

In the meta-regression, the prevalence of suicidal ideation was found to be increased with average age. Generally, those who are older have had more time to experience suicidal ideation or suicide attempts(if the measure is of lifetime suicidal ideation). It may also be attributed to the fact that older homosexual male are under pressure from being pushed to get married or currently living in an unfortunate heterosexual marriage ${ }^{10}$. Therefore, more understanding and support from family and society is required for them.

However, there are several limitations in our research. First, the measured survey point didn't coincide with each other, such as past one month, past six months, past one year and lifetime. As expected, the lifetime prevalence of suicidal ideation and suicide attempts was the highest when comparing with other timeframes. The combined results may represent an underestimate of lifetime ideation and attempts across the entire sample, but a potential overestimate in the context of shorter timeframes. Therefore, it should be cautiously interpreted when drawing on our results. Second, there was substantial heterogeneity between studies. Despite our efforts to explore the sources of heterogeneity, it remained unaddressed in this meta-analysis. Third, non-probability sampling methods were used in all included studies, the extent to which it may unpredictably lead to a bias of the pooled estimates and limit the generalizability of the results. Fourth, there is a potential measurement bias because of the inconsistent definition of suicidal ideation or suicide attempt, and no uniform measurement tools for assessing suicidal ideation or suicide attempts were identified in included studies. Furthermore, the influence of the recall bias generated during the collection of information in individual studies on the combined results still can't be ignored.

\section{Conclusions}

In summary, our meta-analysis provided timely and useful information on the prevalence of suicidal ideation and suicide attempts which had significant public health policy implications. The pooled prevalence of suicidal ideation and suicide attempts were quite high among Chinese MSM, underscoring the importance and urgency of early and effective psychological interventions to address suicide-related problems, especially for HIV-positive MSM.

\section{Abbreviations}

MSM, Men who have sex with men;Cl, confidence interval; CCMD, Chinese Classification of Mental Disorders; PRISMA, Preferred Reporting Items for Systematic reviews and Meta-Analyses; RDS, respondent-driven sampling; SD, Standard Deviation; NR, none reported

\section{Declarations}

\section{Ethics approval and consent to participate: Not applicable.}

Consent for publication: Not applicable.

Authors' contributions: FHL and FTJ designed this study and contributed substantially to the design of the search strategy. FHL and WXB searched and selected the literatures. WXB and CYM participated in the data extraction and critically revised it. FHL and CYM performed the analysis and interpreted the data. FHL drafted the manuscript. YTB and FTJ critically reviewed and proofread the manuscript. All authors read and approved the final manuscript.

Funding: This research did not receive any specific grant from funding agencies in the public, commercial, or not-for-profit sectors. 
Acknowledgements: Not applicable.

Competing interests: The authors declare that they have no competing interests.

Availability of data and materials: All data generated or analysed during this study are included in this published article.

\section{References}

1. Safren SA, Reisner SL, Herrick A, et al. Mental health and HIV risk in men who have sex with men. Journal of acquired immune deficiency syndromes (1999) 2010;55 Suppl 2:S74-7. doi: 10.1097/QAl.0b013e3181fbc939 [published Online First: 2011/03/26]

2. Batchelder AW, Safren S, Mitchell AD, et al. Mental health in 2020 for men who have sex with men in the United States. Sex Health 2017;14(1):59-71. doi: 10.1071/SH16083 [published Online First: 2017/01/06]

3. Sivasubramanian M, Mimiaga MJ, Mayer KH, et al. Suicidality, clinical depression, and anxiety disorders are highly prevalent in men who have sex with men in Mumbai, India: findings from a community-recruited sample. Psychol Health Med 2011;16(4):450-62. doi: 10.1080/13548506.2011.554645 [published Online First: 2011/07/14]

4. Mu H, Li Y, Liu L, et al. Prevalence and risk factors for lifetime suicide ideation, plan and attempt in Chinese men who have sex with men. BMC Psychiatry 2016;16(1) doi: 10.1186/s12888-016-0830-9

5. King M, Semlyen J, Tai SS, et al. A systematic review of mental disorder, suicide, and deliberate self harm in lesbian, gay and bisexual people. BMC Psychiatry 2008;8:70. doi: 10.1186/1471-244X-8-70 [published Online First: 2008/08/19]

6. Meyer IH. Prejudice as stress: conceptual and measurement problems. American journal of public health 2003;93(2):262-5. [published Online First: 2003/01/30]

7. Hu J, Dong Y, Chen X, et al. Prevalence of suicide attempts among Chinese adolescents: A meta-analysis of cross-sectional studies. Comprehensive psychiatry 2015;61:78-89. doi: 10.1016/j.comppsych.2015.05.001 [published Online First: 2015/05/26]

8. Ferlatte O, Dulai J, Hottes TS, et al. Suicide related ideation and behavior among Canadian gay and bisexual men: a syndemic analysis. BMC Public Health 2015;15:597. doi: 10.1186/s12889-015-1961-5 [published Online First: 2015/07/03]

9. Hottes TS, Bogaert L, Rhodes AE, et al. Lifetime Prevalence of Suicide Attempts Among Sexual Minority Adults by Study Sampling Strategies: A Systematic Review and Meta-Analysis. American journal of public health 2016;106(5):e1-12. doi: 10.2105/AJPH.2016.303088 [published Online First: 2016/04/07]

10. Chen $\mathrm{H}$, Li Y, Wang $\mathrm{L}$, et al. Causes of suicidal behaviors in men who have sex with men in China: a national questionnaire survey. BMC public health 2015;15:91. doi: 10.1186/s12889-015-1436-8

11. Swannell S, Martin G, Page A. Suicidal ideation, suicide attempts and non-suicidal self-injury among lesbian, gay, bisexual and heterosexual adults: Findings from an Australian national study. The Australian and New Zealand journal of psychiatry 2016;50(2):14553. doi: 10.1177/0004867415615949 [published Online First: 2015/12/04]

12. Luo Z, Feng T, Fu H, et al. Lifetime prevalence of suicidal ideation among men who have sex with men: A meta-analysis. BMC Psychiatry 2017;17(1) doi: 10.1186/s12888-017-1575-9

13. Liu M, Yu Z, Zhang B, et al. Estimation on the numbers of Chinese homosexuality and people with same-sex sexual behaviors and related female group. The Chinese Journal of Human Sexuality 2015;24(03):117-21.

14. Chinese Society of Psychiatry. Chinese classification and diagnostic criteria of mental disorders (the 3rd version). Shandong: Shandong Publishing House of Science and Technology 2001.

15. Hu Y. Sex Ideologies in China: Examining Interprovince Differences. Journal of sex research2016;53(9):1118-30. doi: 10.1080/00224499.2015.1137272 [published Online First: 2016/02/18]

16. Xie Y, Peng M. Attitudes Toward Homosexuality in China: Exploring the Effects of Religion, Modernizing Factors, and Traditional Culture. J Homosex 2018;65(13):1758-87. doi: 10.1080/00918369.2017.1386025 [published Online First: 2017/09/29]

17. Wang YY, Dong M, Zhang Q, et al. Suicidality and clinical correlates in Chinese men who have sex with men (MSM) with HIV infection. Psychology, health \& medicine 2019;24(2):137-43. doi: 10.1080/13548506.2018.1515495

18. Mo PKH, Lau JTF, Wu X. Relationship between illness representations and mental health among HIV-positive men who have sex with men. AIDS Care - Psychological and Socio-Medical Aspects of AIDS/HIV 2018;30(10):1246-51. doi: 10.1080/09540121.2018.1445825

19. Chen W. Study on Population Characteristics and HIV Infection Status of Transgender Women [Thesis]. Shandong University, 2016.

20. Moher D, Liberati A, Tetzlaff J, et al. Preferred reporting items for systematic reviews and meta-analyses: the PRISMA statement. J Clin Epidemiol 2009;62(10):1006-12. doi: 10.1016/j.jclinepi.2009.06.005 [published Online First: 2009/07/28]

21. Stroup DF, Berlin JA, Morton SC, et al. Meta-analysis of observational studies in epidemiology: a proposal for reporting. Meta-analysis Of Observational Studies in Epidemiology (MOOSE) group. JAMA 2000;283(15):2008-12. [published Online First: 2000/05/02]

Page $6 / 13$ 
22. Salway T, Ross LE, Fehr CP, et al. A Systematic Review and Meta-Analysis of Disparities in the Prevalence of Suicide Ideation and Attempt Among Bisexual Populations. Arch Sex Behav 2019;48(1):89-111. doi: 10.1007/s10508-018-1150-6 [published Online First: 2018/03/02]

23. Zhang DD, Hong H, Jiang HB. Depression in men who have sex with men in Ningbo. Preventive Medicine 2018;30(5):442-45. doi: 10.19485/j.cnki.issn2096-5087.2018.05.003

24. Wang Y, Li LL, Zhou WM, et al. Suicide behaviors and influencing factors among young men who have sex with men in Mianyang, China. Chinese Journal of Viral Diseases 2018;8(5):370-74. doi: 10.16505/j.2095-0136.2018.0080

25. Li J, Liu J, Li Y, et al. Association between impulsivity, aggression, and suicide among men who have sex with men (MSM) in Foshan city. Chinese Journal of AIDS \& STD 2018;24(11):1110-14. doi: 10.13419/j.cnki.aids.2018.11.10

26. Zheng JT. Study on the behavioral characteristic and their influencing factors in men who have sex with men among college students [Thesis]. Shandong University 2017.

27. Zhao Q, Sun MQ, Wang JF. Status of homosexual and bisexual behaviors and related factors among college students in Nanjing City. Chinese Journal of Health Education 2017;33(12):1073-76.

28. Liu Y, Peng BH, Niu L, et al. Emotional problems among newly diagnosed HIV-positive men with homosexual sex behaviors. Chinese Mental Health Journal 2017;31(6):471-77. doi: 10.3969/j.issn.1000-6729.2017.06.009

29. Li RH. Study on HIV prevalence, HIV testing rate and their associated factors among men who have sex with men in Zhengjiang Province [Thesis]. Ningbo University, 2017.

30. Yu Y, Wu T, Li Y, et al. Gay Men's Gender Roles and Mental Health in Guangzhou. China Journal of Health Psychology 2016;24(11):161821,22. doi: 10.13342/j.cnki.cjhp.2016.11.006

31. Li R, Cai Y, Wang Y, et al. Psychosocial syndemic associated with increased suicidal ideation among men who have sex with men in Shanghai, China. Health Psychology 2016;35(2):148-56. doi: 10.1037/hea0000265

32. Yang HY. Study on the HIV/AIDS-related stigma and discrimination within MSM community [Thesis]. Anhui Medical University, 2015.

33. Chen F, Ding F, Lin XJ, et al. Prevalence rates of depression and anxiety in HIV-infected men who have sex with men. Chinese Mental Health Journal 2015(4):251-57. doi: 10.3969/j.issn.1000-6729.2015.04.003

34. Wu Y, Yang H, Wang J, et al. Prevalence of suicidal ideation and associated factors among HIV-positive MSM in Anhui, China. International Journal of STD and AIDS 2015;26(7):496-503. doi: 10.1177/0956462414544722

35. Yu Y. Study on Gay Men's Mental Health [Thesis]. Sun Yat-sen University, 2012.

36. Zheng JD, Pang L, Xu J, et al. Epidemiological study on the prevalence of HIV and syphilis and their correlates among male university students who have sex with men in Beijing, China. Chinese Journal of AIDS \& STD 2011;17(3):358-59,62.

37. Xue LJ, Wang WM, Xu Y, et al. An online-survey of HIV related knowledge and high risk behaviors,social pressure and their influencing factors among MSM. Chinese Journal of AIDS \& STD 2011;17(3):324-27.

38. Yu Y. Study on Gay Men's Living Conditions in Changsha [Thesis]. Central South University, 2010.

39. Wang Y, Zhang HB, Xu J, et al. Analysis on Suicidal Behavior of MSM and Its Influencing Factors. Practical Preventive Medicine 2010;17(5):833-36. doi: 10.3969/j.issn.1006-3110.2010.05.001

40. Zhang BC, Li XF, Chu QS, et al. Correlation between AIDS and homosexuals: A study of 2046 male homosexuals in nine major cities of China. The Chinese Journal of Human Sexuality 2008(08):6-10.

41. Zhang HB, Wang JJ, Zheng YJ, et al. Relationship between suicide behaviors and social character among men having sex with men in Hefei. Chinese Journal of Public Health 2007;23(9):1027-29. doi: 10.3321/j.issn:1001-0580.2007.09.002

42. Cao XL, Zhong BL, Xiang YT, et al. Prevalence of suicidal ideation and suicide attempts in the general population of China: A meta-analysis. Int J Psychiatry Med 2015;49(4):296-308. doi: 10.1177/0091217415589306 [published Online First: 2015/06/11]

43. Wu Z. Characteristics of HIV sexually transmission and challenges for controlling the epidemic in China. Chinese Journal of Epidemiology 2018;39(6):707-09. doi: 10.3760/cma.j.issn.0254-6450.2018.06.002

44. Wang T, Fu H, Kaminga AC, et al. Prevalence of depression or depressive symptoms among people living with HIV/AIDS in China: a systematic review and meta-analysis. BMC Psychiatry 2018;18(1):160. doi: 10.1186/s12888-018-1741-8 [published Online First: 2018/06/02]

45. Ferlatte O, Salway T, Oliffe JL, et al. Stigma and suicide among gay and bisexual men living with HIV. AIDS Care 2017;29(11):1346-50. doi: 10.1080/09540121.2017.1290762 [published Online First: 2017/03/11]

46. Badiee J, Moore DJ, Atkinson JH, et al. Lifetime suicidal ideation and attempt are common among HIV+ individuals. Journal of affective disorders 2012;136(3):993-9. doi: 10.1016/j.jad.2011.06.044 [published Online First: 2011/07/26] 
47. Zhang BC, Hu TZ, Li XF, et al. The relationship between AIDS high risk behaviors and childhood status, attitude/perception to gender/sex orientation and rare experiences/psychology among homosexuals in China. Chin J STD/AIDS Prev Cont 2002;8(2):84-87. doi: 10.3969/j.issn.1672-5662.2002.02.006

48. Zhang BC, Li XF, Wu SW, et al. Survey of homosexual and bisexual males' psychology and related condition in China Today. Chinese Journal of Human Sexuality 2003(03):16-18+15.

49. Zheng YJ, Xu J, Zhao B, et al. Psychosocial distiction of men who have sex with men Chinese Journal of Behavioral Medical Science 2004(06):59-61.

50. Badowski G, Somera LP, Simsiman B, et al. The efficacy of respondent-driven sampling for the health assessment of minority populations. Cancer Epidemiol 2017;50(Pt B):214-20. doi: 10.1016/j.canep.2017.07.006 [published Online First: 2017/11/10]

51. Ludlam AH, Saxton PJ, Dickson NP, et al. Respondent-driven sampling among gay and bisexual men: experiences from a New Zealand pilot study. BMC Res Notes 2015;8:549. doi: 10.1186/s13104-015-1449-5 [published Online First: 2015/10/11]

\section{Tables}

Table 1 Characteristics of the 23 studies on the prevalence of suicidal ideation and suicide attempts.

\begin{tabular}{|c|c|c|c|c|c|c|c|c|c|c|}
\hline & $\begin{array}{c}\text { Survey } \\
\text { dates }\end{array}$ & Location, City & Area & $\begin{array}{l}\text { Sampling } \\
\text { method }\end{array}$ & $\begin{array}{l}\text { Method of } \\
\text { data } \\
\text { collection }\end{array}$ & Age, y & Sample size & $\begin{array}{c}\text { No. } \\
\text { Suicidal } \\
\text { ideation }\end{array}$ & $\begin{array}{c}\text { No. } \\
\text { Suicide } \\
\text { attempts }\end{array}$ & $\begin{array}{c}\text { Survey } \\
\text { point }\end{array}$ \\
\hline 17 & $\begin{array}{l}2015- \\
2017\end{array}$ & Shenzhen & Southern & non-RDS & NR & $>18$ & $\begin{array}{l}\text { HIV-positive: } \\
410\end{array}$ & 42 & 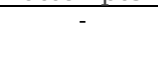 & $\begin{array}{c}\text { past } \\
\text { month }\end{array}$ \\
\hline $3^{23}$ & $\begin{array}{l}2016.07- \\
2016.12\end{array}$ & Ningbo & Southern & non-RDS & face-to-face & Mean(SD):31.1(8.4) & 516 & 93 & - & lifetime \\
\hline 4 & $\begin{array}{l}2015.09- \\
2017.06\end{array}$ & Mianyang & Southern & non-RDS & $\begin{array}{c}\text { self- } \\
\text { administered }\end{array}$ & $\begin{array}{l}\text { Median(Range) :21.0(16- } \\
24)\end{array}$ & 355 & 70 & 23 & lifetime \\
\hline $3^{25}$ & $\begin{array}{l}2010.07- \\
2011.01\end{array}$ & Foshan & Southern & RDS & face-to-face & Mean(SD):31.9(8.5) & 249 & 84 & 23 & lifetime \\
\hline$\underset{18}{\mathrm{~K}}$ & $\begin{array}{l}2010.10- \\
2011.09\end{array}$ & Chengdu & Southern & non-RDS & face-to-face & Mean(SD):32.2(10.5) & 225 & 108 & 6 & lifetime \\
\hline 26 & 2016.10 & Qingtao & Northern & non-RDS & $\begin{array}{c}\text { self- } \\
\text { administered }\end{array}$ & Mean(SD) :20.6(1.6) & $\begin{array}{c}\text { HIV- } \\
\text { positive:300 }\end{array}$ & 21 & - & lifetime \\
\hline 7 & 2015 & Nanjing & Southern & non-RDS & $\begin{array}{c}\text { self- } \\
\text { administered }\end{array}$ & NR & 194 & 45 & 32 & lifetime \\
\hline 8 & $\begin{array}{l}2013.03- \\
2014.09\end{array}$ & Changsha & Southern & non-RDS & NR & Mean(SD):29.0(8.0) & $\begin{array}{c}\text { HIV- } \\
\text { positive:321 }\end{array}$ & 96 & 10 & lifetime \\
\hline 729 & $\begin{array}{l}2013.12- \\
2014.10\end{array}$ & $\begin{array}{c}\text { Wenzhou, Ningbo, } \\
\text { Hangzhou }\end{array}$ & Southern & RDS & face-to-face & $>14$ & $\begin{array}{c}\text { Total:1308 } \\
\text { HIV- } \\
\text { positive:192 } \\
\text { HIV- } \\
\text { negative:1116 }\end{array}$ & $\begin{array}{c}\text { Total: } 149 \\
\text { HIV- } \\
\text { positive:30 } \\
\text { HIV- } \\
\text { negative:119 }\end{array}$ & - & $\begin{array}{l}\text { past } \\
\text { year }\end{array}$ \\
\hline 0 & $\begin{array}{l}2014.01- \\
2015.03\end{array}$ & Guangzhou & Southern & RDS & $\begin{array}{c}\text { self- } \\
\text { administered }\end{array}$ & $\begin{array}{l}\text { Median(Range):26.0(18- } \\
\text { 38) }\end{array}$ & 420 & 123 & - & $\begin{array}{l}\text { past } \\
\text { year }\end{array}$ \\
\hline $\mathrm{j}^{19}$ & $\begin{array}{l}2015.10- \\
2016.01\end{array}$ & Qingdao, Jinan & Northern & non-RDS & face-to-face & Mean(SD):29.8(6.5) & 62 & 20 & 11 & lifetime \\
\hline 4 & $\begin{array}{l}2008.04- \\
2009.01\end{array}$ & $\begin{array}{c}\text { Anshan, Benxi, } \\
\text { Dandong, Shenyang }\end{array}$ & Northern & RDS & face-to-face & $\operatorname{Mean}(\mathrm{SD}): 27.2(0.3)$ & 807 & 148 & 37 & lifetime \\
\hline 1 & $\begin{array}{l}2014.03- \\
2014.05\end{array}$ & Shanghai & Southern & non-RDS & face-to-face & Mean (Range) $: 30.5$ (17- & 547 & 58 & - & $\begin{array}{l}\text { past } \\
\text { year }\end{array}$ \\
\hline$; 32$ & $\begin{array}{l}2013.04- \\
2013.07\end{array}$ & $\begin{array}{l}\text { Hefei, Maanshan, } \\
\text { Wuhu }\end{array}$ & Southern & non-RDS & face-to-face & $\begin{array}{c}\text { Mean (Range) } \\
62)\end{array}$ & $\begin{array}{c}\text { Total:386 } \\
\text { HIV- } \\
\text { positive:184 } \\
\text { HIV- } \\
\text { negative:202 }\end{array}$ & $\begin{array}{c}\text { Total:70 } \\
\text { HIV- } \\
\text { positive:57 } \\
\text { HIV- } \\
\text { negative:13 }\end{array}$ & - & $\begin{array}{l}\text { past six } \\
\text { months }\end{array}$ \\
\hline 3 & $\begin{array}{l}2012.12- \\
2013.05\end{array}$ & $\begin{array}{l}\text { Guangzhou, } \\
\text { Chongqing, } \\
\text { Chengdu }\end{array}$ & Southern & non-RDS & $\begin{array}{c}\text { self- } \\
\text { administered }\end{array}$ & Range:18-63 & $\begin{array}{l}\text { HIV- } \\
\text { positive: } 541\end{array}$ & 116 & - & $\begin{array}{l}\text { past } \\
\text { year }\end{array}$ \\
\hline 34 & $\begin{array}{l}2013.03- \\
2013.06\end{array}$ & $\begin{array}{c}\text { Hefei, Maanshan, } \\
\text { Wuhu }\end{array}$ & Southern & non-RDS & face-to-face & Mean(SD):31.4(9.2) & $\begin{array}{l}\text { HIV- } \\
\text { positive: } 184\end{array}$ & - & 10 & $\begin{array}{l}\text { past six } \\
\text { months }\end{array}$ \\
\hline 5 & $\begin{array}{l}2011.10- \\
2012.03\end{array}$ & GuangzhouChengdu & Southern & RDS & face-to-face & $>18$ & 222 & 64 & 6(lifetime) & $\begin{array}{l}\text { past } \\
\text { year }\end{array}$ \\
\hline 36 & $\begin{array}{l}2007.09- \\
2007.12\end{array}$ & Beijing & Northern & non-RDS & $\begin{array}{c}\text { self- } \\
\text { administered }\end{array}$ & $\begin{array}{l}\text { Median(Range) }: 23.0(17- \\
32 \text { ) }\end{array}$ & 157 & 22 & 8 & lifetime \\
\hline 37 & 2010.04 & NR & NR & non-RDS & $\begin{array}{l}\text { self- } \\
\text { administered }\end{array}$ & Mean(SD):28.7(7.5) & 838 & 160 & 97 & lifetime \\
\hline 8 & $\begin{array}{l}2009.03- \\
2009.12\end{array}$ & Changsha & Southern & non-RDS & face-to-face & $\begin{array}{c}\text { Median(Range) } \\
44)\end{array}$ & 418 & 128 & 10 & $\begin{array}{l}\text { past } \\
\text { year }\end{array}$ \\
\hline 9 & $\begin{array}{l}2007.01- \\
2007.02\end{array}$ & Mianyang & Southern & RDS & $\begin{array}{c}\text { self- } \\
\text { administered }\end{array}$ & Mean(SD):24.7(6.5) & 201 & 18 & 7 & past six \\
\hline $3^{40}$ & $\begin{array}{l}2005.12- \\
2006.04\end{array}$ & $\begin{array}{c}\text { Haerbin, } \\
\text { Senyang, } \\
\text { Zhengzhou, etc. }\end{array}$ & $\begin{array}{l}\text { Northern, } \\
\text { Southern }\end{array}$ & non-RDS & NR & Mean(SD):29.4(9.3) & 1956 & 397 & 192 & lifetime \\
\hline 741 & $\begin{array}{l}2005.03- \\
2005.12\end{array}$ & Hefei & Southern & RDS & face-to-face & $\begin{array}{c}\text { Mean (Range) } \\
42)\end{array} 23.3$ (18- & 228 & 24 & 26 (lifetime) & $\begin{array}{c}\text { past } \\
\text { month }\end{array}$ \\
\hline
\end{tabular}

Abbreviations: MSM, men who have sex with men; RDS, respondent-driven sampling; SD, Standard Deviation; NR, none reported. 
Table 2 Subgroup analyses for studies on the prevalence of suicidal ideation and suicide attempts

\begin{tabular}{|c|c|c|c|c|c|c|c|c|c|c|}
\hline \multirow{2}{*}{$\begin{array}{l}\text { Study or sample } \\
\text { characteristics }\end{array}$} & \multicolumn{5}{|c|}{ Suicidal ideation } & \multicolumn{5}{|c|}{ Suicide attempt } \\
\hline & $\begin{array}{l}\text { No. Suicidal } \\
\text { ideation }\end{array}$ & $\begin{array}{l}\text { Total } \\
\text { No. }\end{array}$ & $\begin{array}{l}\text { Combined } \\
\text { prevalence } \\
\%(95 \% \mathrm{CI})\end{array}$ & $\overline{I^{2}}$ & $\bar{P}$ & $\begin{array}{l}\text { No. Suicide } \\
\text { attempt }\end{array}$ & $\begin{array}{l}\text { Total } \\
\text { No. }\end{array}$ & $\begin{array}{l}\text { Combined } \\
\text { prevalence } \\
\%(95 \% \mathrm{CI})\end{array}$ & $\overline{I^{2}}$ & $\bar{P}$ \\
\hline Jverall & 2056 & 10664 & $\begin{array}{l}20.1(16.7 \\
23.7)\end{array}$ & $94.8 \%$ & $<0.001$ & 507 & 6412 & $6.8(5.0,8.9)$ & $88.00 \%$ & $<0.001$ \\
\hline $\begin{array}{l}\text { Survey dates } \\
2010 \text { before }\end{array}$ & 737 & 3763 & $16.9(12.2$ & $92.30 \%$ & $<0.001$ & 289 & 3767 & $6.3(3.9,9.2)$ & $88.30 \%$ & $<0.001$ \\
\hline 2010 after & 1319 & 6897 & $\begin{array}{l}21.4(16.9 \\
26.4)\end{array}$ & $95.60 \%$ & $<0.001$ & 218 & 2645 & $7.3(4.4,10.9)$ & $89.10 \%$ & $<0.001$ \\
\hline $\begin{array}{l}\text { Jity } \\
\text { Southern city }\end{array}$ & 1448 & 7382 & 20.1(16.7, & $95.50 \%$ & $<0.001$ & 259 & 3430 & $6.5(4.2,9.2)$ & $87.90 \%$ & $<0.001$ \\
\hline $\begin{array}{l}\text { Northern city } \\
\text { jampling method }\end{array}$ & 211 & 1326 & $16.2(8.8,25.3)$ & $91.90 \%$ & $<0.001$ & 56 & 1028 & $7.4(2.8,13.8)$ & $82.90 \%$ & $<0.001$ \\
\hline Non-RDS & 1446 & 7221 & $\begin{array}{l}20.5(16.5 \\
248)\end{array}$ & $94.40 \%$ & $<0.001$ & 408 & 4705 & $7.4(5.1,10.1)$ & $88.50 \%$ & $<0.001$ \\
\hline RDS & 610 & 3443 & $\begin{array}{l}19.2(12.8 \\
26.7)\end{array}$ & $95.90 \%$ & $<0.001$ & 99 & 1707 & $5.9(3.3,9.1)$ & $82.80 \%$ & $<0.001$ \\
\hline $\begin{array}{l}\text { Method of data } \\
\text { sollection }\end{array}$ & & & & & & & & & & \\
\hline Self-administered & 535 & 2643 & $\begin{array}{l}19.5(14.1 \\
25.5)\end{array}$ & $92.00 \%$ & $<0.001$ & 167 & 1740 & $8.2(4.6,12.6)$ & $87.50 \%$ & $<0.001$ \\
\hline Face-to-face & 647 & 3344 & $\begin{array}{l}22.5(16.5 \\
29.0)\end{array}$ & $96.30 \%$ & $<0.001$ & 138 & 2395 & $6.1(3.9,8.7)$ & $81.00 \%$ & $<0.001$ \\
\hline $\begin{array}{l}\text { IIV infection* } \\
\text { HIV-positive }\end{array}$ & 463 & 1904 & $\begin{array}{l}27.1(17.6, \\
37.8)\end{array}$ & $95.70 \%$ & $<0.001$ & - & - & - & - & - \\
\hline HIV-negative & 150 & 1318 & $12.4(8.2,17.3)$ & $71.6 \%$ & $<0.001$ & - & - & - & - & - \\
\hline
\end{tabular}

* Significant difference in the prevalence of suicidal ideation by HIV infection $(P<0.05)$.

"-" No available data

Abbreviations: MSM, men who have sex with men;RDS, respondent-driven sampling; CI, confidence interval

\section{Figures}




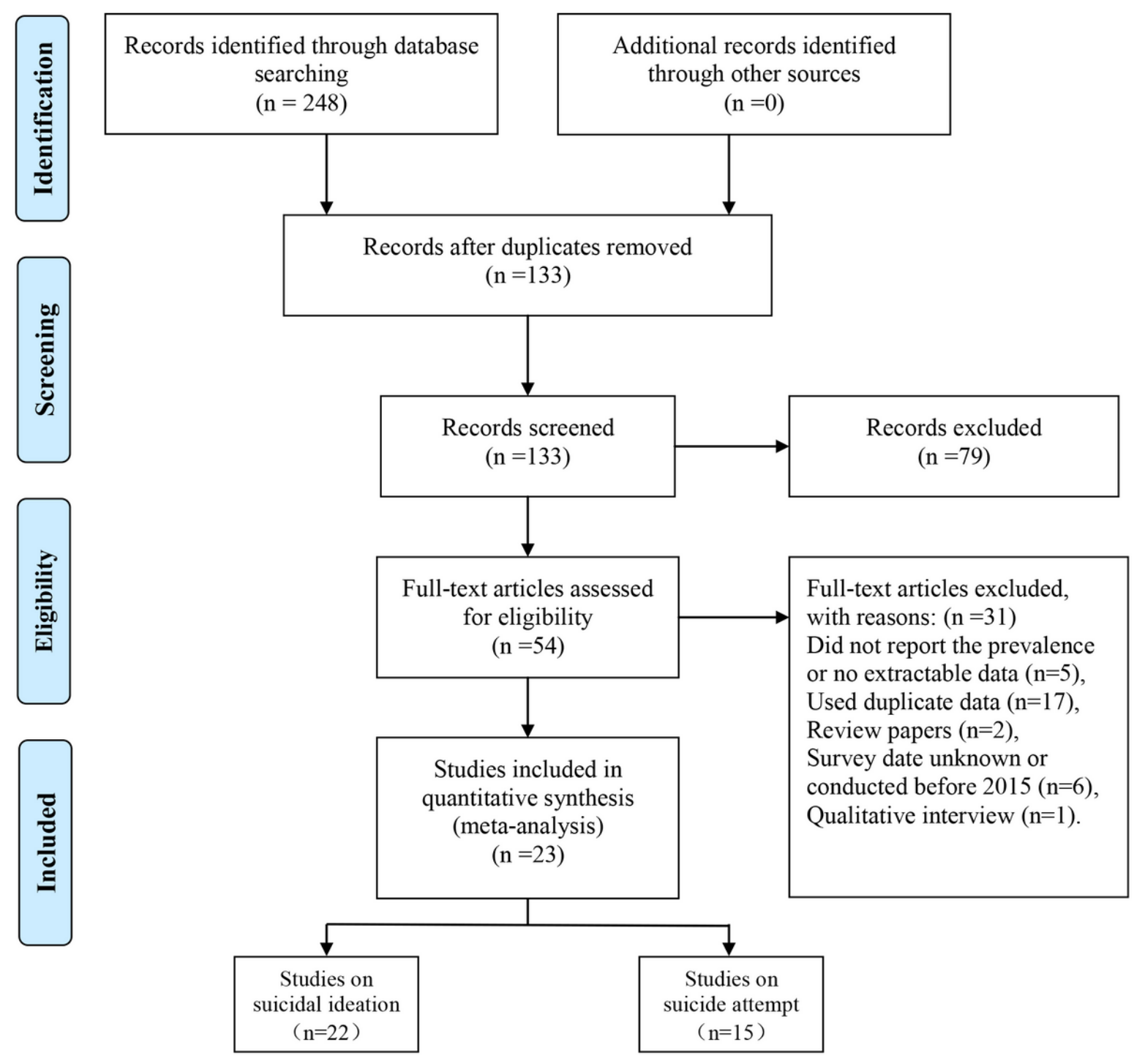

Figure 1

Flowchart for the selection of studies. 
Suicidal ideation over lifetime Zhang DD/2018

Wang $Y / 2018$

Li J/2018

Mo P. K. H./2018

Zheng JT/2017

Zhao Q/2017

Liu $Y / 2017$

Chen WK/2016

$\mathrm{Mu} \mathrm{HJ} / 2016$

Zheng JD/2011

Xue LJ/2011

Zhang BC/2008

Random effects model

Heterogeneity: $I^{2}=93.9 \%, \tau^{2}=0.008, p<0.001$

Suicidal ideation over past year

$\begin{array}{ll}\mathrm{Li} \mathrm{RH} / 2017 & 149 \\ \mathrm{Yu} \mathrm{Y} / 2016 & 123\end{array}$

Yu Y/2016

Li R/2016

Chen F/2015

Yu Y/2012

Yu Y/2010

Random effects model

Heterogeneity: $I^{2}=96.8 \%, \tau^{2}=0.014, p<0.001$

Suicidal ideation over past 6 months

Yang HY/2015

Wang $Y / 2010$

70

Random effects model

Heterogeneity: $I^{2}=89.4 \%, \tau^{2}=0.008, p=0.002$

\section{Suicidal ideation over past month}

$\begin{array}{ll}\text { Wang YY/2019 } & 42 \\ \text { Zhang HB/2007 } & 24\end{array}$

Random effects model $\quad 66$

Heterogeneity: $I^{2}=0 \%, \tau^{2}=0, p=0.888$

Random effects model 2056

Heterogeneity: $I^{2}=94.8 \%, \tau^{2}=0.010, p<0.001$

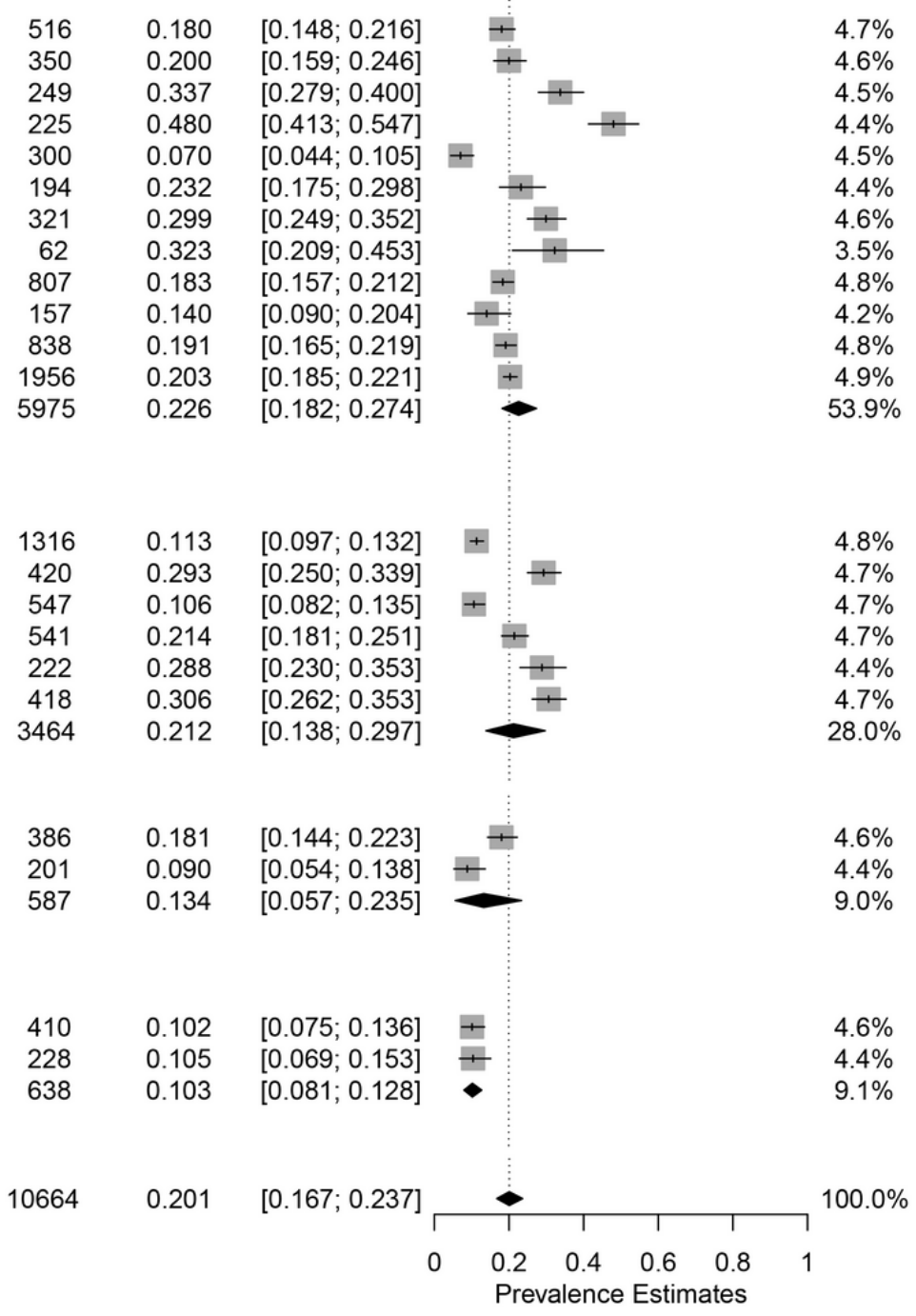

Figure 2

Forest plot of lifetime prevalence of suicidal ideation. 
Suicide attempt over lifetime

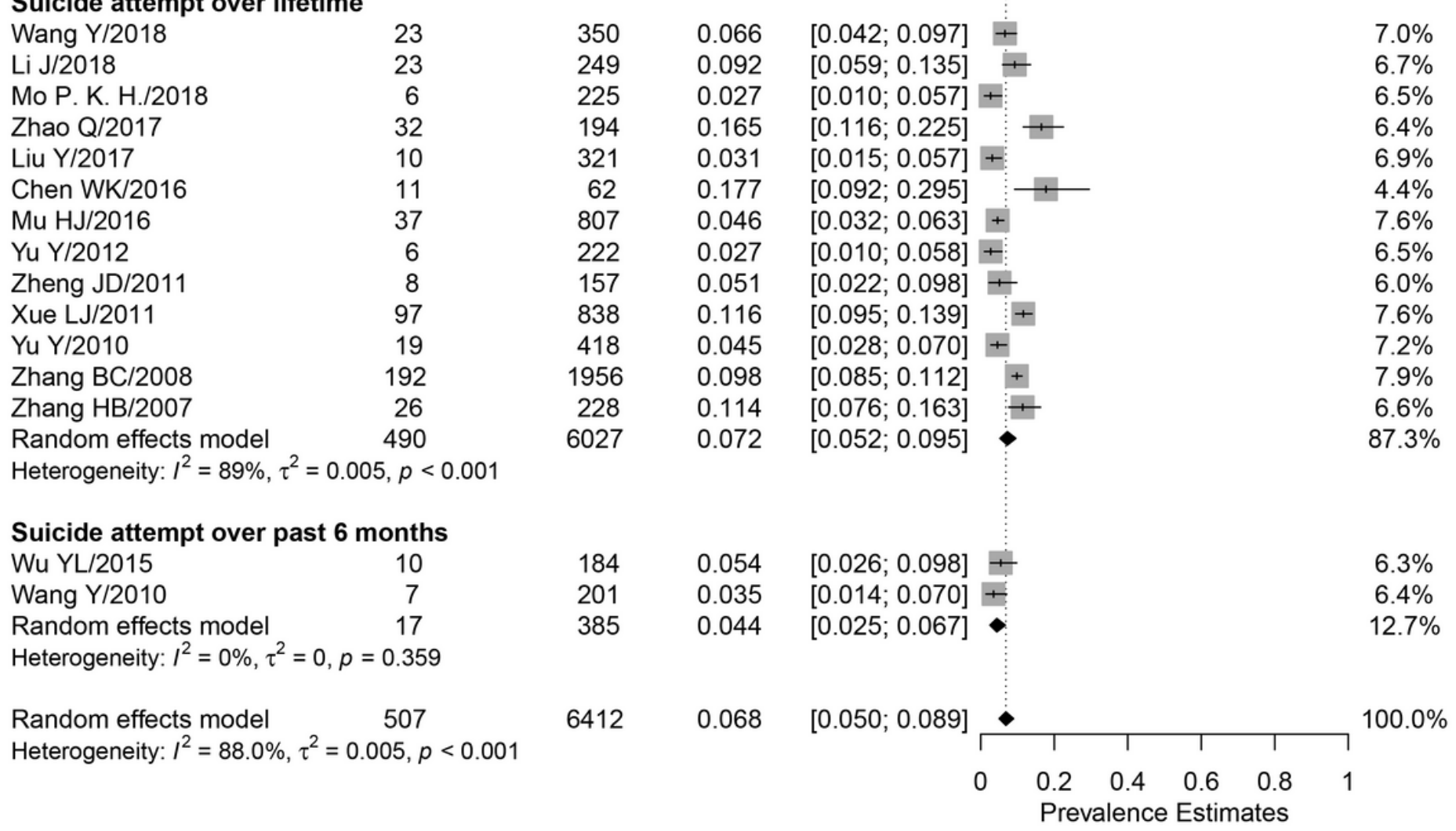

Figure 3

Forest plot of lifetime prevalence of suicide attempt.

(a)

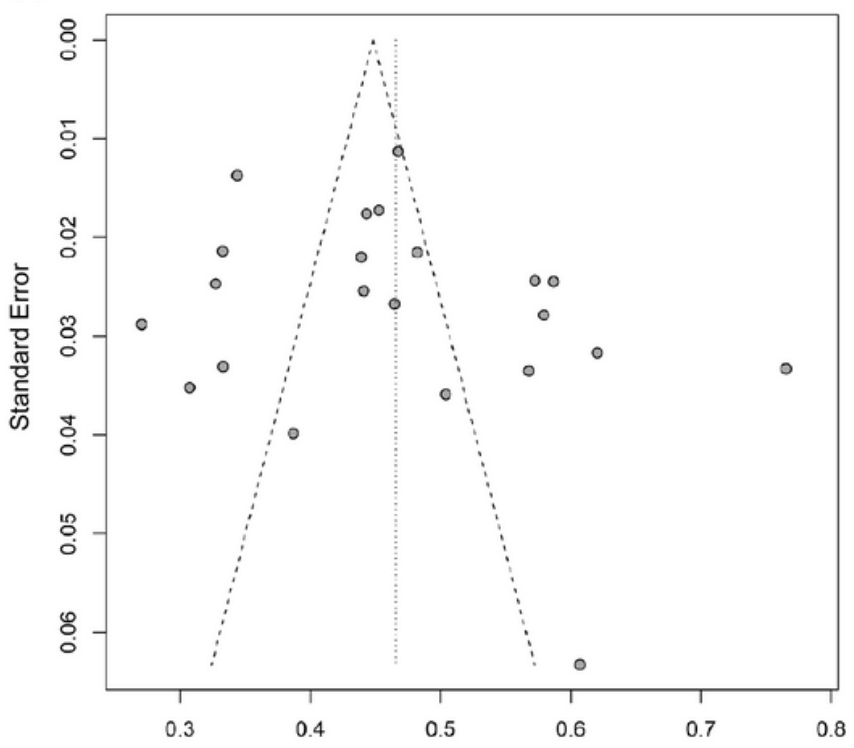

Freeman-Tukey Double Arcsine Transformed Proportion Egger's test: $\mathrm{t}=1.096 P=0.286$ (b)

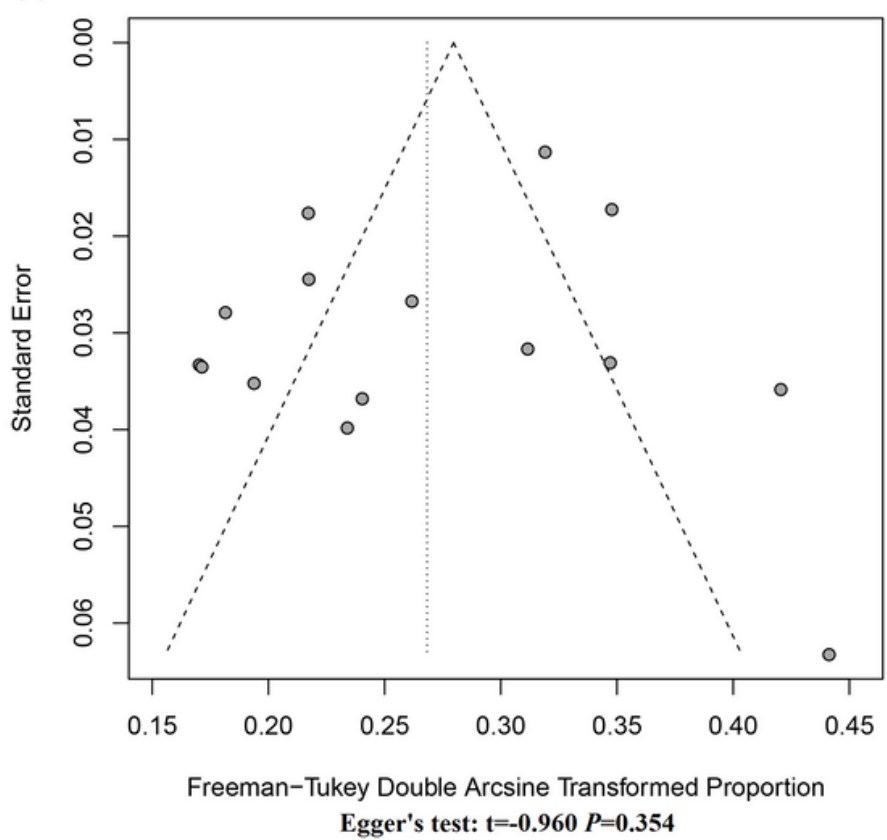

Figure 4

Funnel plots of the included studies with corresponding Egger's tests results. (a) Studies on suicidal ideation, (b) Studies on suicide attempts. 


\section{Supplementary Files}

This is a list of supplementary files associated with this preprint. Click to download.

- Supplementaryfile.docx 